Retraction

\title{
Retracted: Antioxidant Activity and Characterization of One New Polysaccharide Obtained from Perigord Truffle (Tuber huidongense)
}

\author{
Evidence-Based Complementary and Alternative Medicine
}

Received 28 November 2017; Accepted 28 November 2017; Published 14 January 2018

Copyright ( 2018 Evidence-Based Complementary and Alternative Medicine. This is an open access article distributed under the Creative Commons Attribution License, which permits unrestricted use, distribution, and reproduction in any medium, provided the original work is properly cited.

Evidence-Based Complementary and Alternative Medicine has retracted the article titled "Antioxidant Activity and Characterization of One New Polysaccharide Obtained from Perigord Truffle (Tuber huidongense)" [1] at the request of the authors. The first author says the HPLC and NMR results are not reproducible, while the fourth author did not approve the article's submission and disputes the authorship.

\section{References}

[1] Y.-F. Chen, W.-W. Jiang, S.-Q. Zhang, J.-Q. Kan, and Y. Liang, "Antioxidant Activity and Characterization of One New Polysaccharide Obtained from Perigord Truffle (Tuber huidongense)," Evidence-Based Complementary and Alternative Medicine, vol. 2016, Article ID 3537193, 7 pages, 2016. 


\title{
Antioxidant Activity and Characterization of One New Polysaccharide Obtained from Perigord Truffle (Tuber huidongense)
}

\author{
Yong-Feng Chen, ${ }^{1,2}$ Wen-wen Jiang, ${ }^{3}$ Shi-qi Zhang, Jian-quan Kan, ${ }^{4}$ and Yong Liang ${ }^{2}$ \\ ${ }^{1}$ Department of Basic Medical Sciences, School of Medicine, Taizhou University, Taizhou 318000, Zhejiang, China \\ ${ }^{2}$ Institute of Tumor, School of Medicine, Taizhou University, Taizhou, Zhejiang 318000, China \\ ${ }^{3}$ Center of Drug Metabolism and Pharmacokinetics, China Pharmaceutical University, Jiangsu 210009, China \\ ${ }^{4}$ Department of Food Science, Southwest University, Chongqing 400715, China
}

Correspondence should be addressed to Jian-quan Kan; ganjianquan@gmail.com and Yong Liang; liangyongmd@outlook.com

Received 17 March 2016; Revised 19 May 2016; Accepted 7 June 2016

Academic Editor: Gabriel A. Agbor

Copyright ( $) 2016$ Yong-Feng Chen et al. This is an open access article distributed under the Creative Commons Attribution License, which permits unrestricted use, distribution, and reproduction in any medium, provided the original work is properly cited.

\begin{abstract}
As a medicinal and edible fungus parasitizing on the trees, Perigord Truffle (Tuber huidongense) is well known for its delicious taste, unique smell, and high medical value for healthcare. One new water-soluble nonstarch polysaccharide (PST-W with the yield of 0.41\%) from Perigord Truffle (Tuber huidongense) was purified and identified on structural characteristics for the first time. The characterizations of PST-W were studied on physicochemical properties, main components of monosaccharide(s), and molecular structure. The monosaccharide compositions of PST-W were studied and identified as glucan, only containing D-glucoses with the molecular structure of $[\rightarrow 6) \alpha$-D-Glcp $(1 \rightarrow 6) \alpha$-D-Glcp $(1 \rightarrow]_{n}$ by methylation analysis and NMR. In the determination of total reducing capacity, the reducing abilities of polysaccharide extracts could be listed as vitamin C $>$ PST-W $>$ crude polysaccharides$3>$ crude polysaccharides- $2>$ crude polysaccharides- 1 . All of PST-W, crude polysaccharides- 2 , and crude polysaccharides- 3 were relatively good scavenger for 1,1-Diphenyl-2-picrylhydrazyl radical 2,2-Diphenyl-1-(2,4,6-trinitrophenyl)hydrazyl radicals with IC $_{50}$ of $2.81,4.17$, and $3.44 \mathrm{mg} / \mathrm{mL}$, respectively. However, $\mathrm{O}_{2}{ }^{-\bullet}$ clearing abilities of PST-W and crude polysaccharides were obviously weaker. The activities of total crude extract were the worst, indicating that the impurities might negatively affect the antioxidant activity. Thus, the separation and purification of polysaccharides were significant to increase the antioxidant activity in some degree.
\end{abstract}

\section{Introduction}

There is a long history on the study of tuber, since botanist Michael recorded this species in 1792 for the first time and fungi scientist Fillet confirmed its position in the taxonomy of fungi in 1823. The polysaccharide of Tuber sinense (PST) is a protein-bound polysaccharide first extracted from the Chinese truffle, and it has been utilized widely for the treatment of tumors. The scientific team of Hu et al. explored the effect of PST on tumor and immune system [1]. It was reported that PST dramatically inhibits the growth of S180 sarcoma and Ehrlich's ascites carcinoma sarcoma in vivo, but there was no related effect on cell proliferation in vitro, which meant that the antitumor effect of PST might be related to immunomodulation but not cytotoxic activity. In another side, PST therapy increased the weight of mouse spleen and the level of serum antibodies, which proved the assumption as well. As a fungous polysaccharide with low toxicity and good water solubility, PST showed significant antitumor potential and might have much more medicinal value. The research group of Tang et al. not only aimed to increase the production of extracellular polysaccharides in the plantation area of medicinal mushroom Chinese truffle Tuber sinense [2] but also separated more than fifty-two polysaccharides from the fermentation systems of Tuber melanosporum, Tuber indicum, Tuber sinense, and Tuber aestivum and the fruiting bodies of Tuber indicum, Tuber himalayense, and Tuber sinense by elution with an activated carbon column. The 
polysaccharides from Tuber fermentation system exhibited relatively higher in vitro antitumor activity against HepG2, A549, HCT-116, SK-BR-3, and HL-60 cells than those from Tuber fruiting bodies [3]. Besides, the specific aromas and polysaccharides of Perigord Truffle had been exploited on plenty of special pharmacological effects, such as sexual performance improving, antitumor effects, and antiaging effects $[2,4,5]$.

As a medicinal and edible fungus parasitizing on the trees, the wild Perigord Truffle (Tuber huidongense, Huidong city of Sichuan province in China) was obtained as experimental subject by our research team for several years. Sixty-five main compounds of truffle aroma were identified, including most components of alcohols and lipids by GS-MS [6]. According to the previous study on the new water-soluble nonstarch polysaccharide (PST-W) from Perigord Truffle (Tuber huidongense), it indicated that the molecular weight of PST-W was $7.29 \times 10^{5}$ Da approximately [7]. Studying physicochemical properties and compositions of PST-W would do help to understand its potential antioxidant activity and other pharmacological activities, which will also provide reference and basis for the main pharmacological activity of truffle and its corresponding mechanisms. Therefore, the systematic study on its components of aromas and polysaccharides will be meaningful for its potential utilization with broad market prospect.

\section{Methods}

2.1. The Source of the Truffles. The source of Tuber huidongense is from Huidong city of Sichuan province in China. All sources, identified by Dr. Jian-quan Kan, were frozen and vacuum-packed.

2.2. Polysaccharide Purification and Purity Identification. Main processes were described in Figure 1. The yields of samples in each part were calculated after freeze drying. The purity of PST-W was detected by Shimadzu HPLC with RID10AT detector (differential detection). Pump was IC-10AT with a Cosmosil amino column $(4.6 \times 250 \mathrm{~mm})$. The injection volume was $20 \mu \mathrm{L}$ at $25^{\circ} \mathrm{C}$ with flow rate of $0.4 \mathrm{~mL} / \mathrm{min}$, and the wavelength of detection was at $197 \mathrm{~nm}$ with the mobile phase of ultrapure water.

\subsection{Structural Characteristics of Polysaccharides}

2.3.1. The Compositions of Monosaccharide. At first, $20.0 \mathrm{mg}$ of polysaccharides was dissolved in $2 \mathrm{~mL}$ of $2 \mathrm{~mol} / \mathrm{L}$ trifluoroacetic acid. The reaction solution was sealed and fully hydrolyzed at $100^{\circ} \mathrm{C}$ for $8 \mathrm{~h}$. The reaction vessel was removed out and cooled down to room temperature. After centrifugation at $1000 \mathrm{rpm}$ for $5 \mathrm{~min}$, the supernatant was neutralized with $\mathrm{NaOH}$ to $\mathrm{pH} 7.0$ and freeze-dried as the hydrolyzates of polysaccharides.

The monosaccharide derivatives were prepared before HPLC analysis. $80 \mu \mathrm{L}$ of each standard monosaccharide solution $(0.2 \mathrm{~mol} / \mathrm{L})$ was accurately measured and mixed in one tube, followed by adding $100 \mu \mathrm{L}$ of $0.3 \mathrm{~mol} / \mathrm{L} \mathrm{NaOH}$ and $1.2 \mathrm{~mL}$ of $0.5 \mathrm{~mol} / \mathrm{L}$ 1-phenyl-3-methyl-5-pyrazolone which

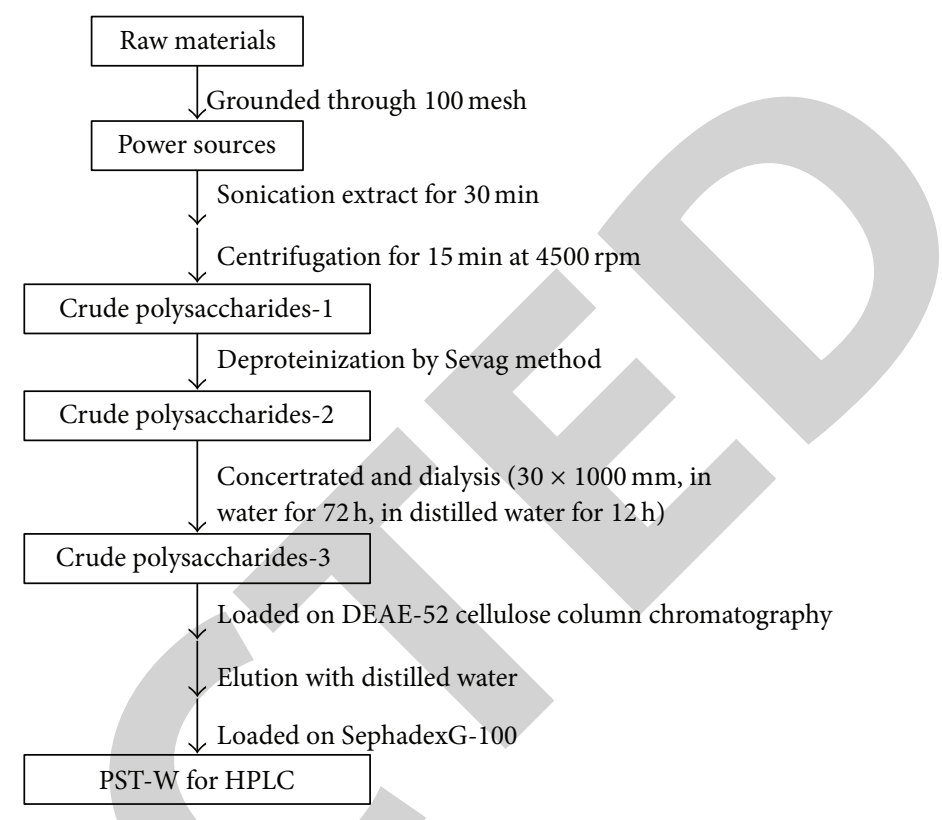

FIgURE 1: The extraction and purification process in detail.

dissolved in methanol. The mixture was denatured at $70^{\circ} \mathrm{C}$ water bath for $40 \mathrm{~min}$ and then cooled down to room temperature and neutralized with $\mathrm{HCl}$. Thereafter, it was extracted for three times with $1 \mathrm{~mL} \mathrm{CHCl}_{3}$; the upper aqueous phase contained the derived products of monosaccharide. The derivatives for hydrolyzates of polysaccharide (PST-W) were also done according to the method mentioned above $[8,9]$.

HPLC-UV detection was conducted in Agilent 1100 chromatographic system with Waters Symmetry C18 column $(150 \times 4.60 \mathrm{~mm})$ at the detecting wavelength of $245 \mathrm{~nm}$. The injection volume was $20 \mu \mathrm{L}$ with flow rate of $1.0 \mathrm{~mL} / \mathrm{min}$ at $40^{\circ} \mathrm{C}$. The mobile phase was ammonium acetate buffer $\left(\mathrm{CH}_{3} \mathrm{COONH}_{4}-\mathrm{CH}_{3} \mathrm{COOH}\right.$, modified to $\mathrm{pH} 6.0$ with acetic acid)-acetonitrile $(85: 15, \mathrm{v} / \mathrm{v})$.

2.3.2. PST-W Methylation Analysis. Two milligrams of PST$\mathrm{W}$ was accurately weighed and vacuum dried at $70^{\circ} \mathrm{C}$ for $3 \mathrm{~h}$. $2 \mathrm{~mL}$ of anhydrous dimethyl sulfoxide was added and stirred till it was dissolved. $1.8 \mathrm{~mol} / \mathrm{L}$ of methylsulfinyl anion was added and followed with nitrogen stream. Abundant precipitations were shown but they disappeared and dissolved again after stirring. $1 \mathrm{~mL}$ of methyl iodide was added dropwise into the solution, which was kept in room temperature below $30^{\circ} \mathrm{C}$ and stirred until a clear pale yellow was shown. After reaction stopped $1 \mathrm{~h}$ later, the methylation products were filled in a dialysis bag to dialyze in the flowing water flow for $24 \mathrm{~h}$. Then it was concentrated and freeze-dried for use. Its methylation level could be checked by IR spectrum. Methylation should be repeated if it is not complete.

Subsequently, the methylated polysaccharide was hydrolyzed and followed with acetylation. The $1 \mathrm{~mL}$ formic acid was added into certain amount of methylated polysaccharide, which was in an Abe tube full of nitrogen. 
It was put in $100^{\circ} \mathrm{C}$ oven to hydrolyze for $6 \mathrm{~h}$. After that, formic acid was moved and followed by $0.5 \mathrm{~mL}$ of $2 \mathrm{~mol} / \mathrm{L}$ trifluoroacetic acid to hydrolyze methylated polysaccharide again in the same process. The products were resolved in $0.5 \mathrm{~mL}$ water and deoxidized by $2 \mathrm{mg}$ sodium borohydride at $30^{\circ} \mathrm{C}$ for $4 \mathrm{~h}$. The next step was acetylation which was realized by pyridine and acetic acid [10]. The acetylation products were dissolved in $1 \mathrm{~mL}$ of methanol. After the organic membrane filtration, the solution can be used for GC-MS analysis.

The GC column was Agilent 122-2932 DB225 (0.25 mm × $30 \mathrm{~m} \times 0.25 \mu \mathrm{m}$ ) followed by MS detector MSD. Temperature program began with initial temperature of $110^{\circ} \mathrm{C}$. The heating rate was $7^{\circ} \mathrm{C} / \mathrm{min}$. And temperature was kept at $230^{\circ} \mathrm{C}$ for $18 \mathrm{~min}$. The temperature at injector was $230^{\circ} \mathrm{C}$. Carrier gas was helium. Injection volume was $1 \mu$ with $1.0 \mathrm{~mL} / \mathrm{min}$ flow rate of carrier gas. According to the data of spectra in standard CCRC database, the connecting bond type of sugar would be confirmed.

2.3.3. NMR Analysis of PST-W. PST-W of $15 \mathrm{mg}$ was dissolved in $0.5 \mathrm{~mL} \mathrm{D}_{2} \mathrm{O}$, using TMS as an internal standard. ${ }^{13} \mathrm{C}$-NMR and ${ }^{1} \mathrm{H}$-NMR spectra were measured by the Bruker AM$400 \mathrm{MHz}$ superconducting NMR instrument.

\subsection{Antioxidative Activity In Vitro}

2.4.1. Determination of Total Reducing Capacity. It was conducted by ferric reducing ability assay [11]. $3.0 \mathrm{~mL}$ of phosphate buffer ( $\mathrm{pH} 6.8,0.2 \mathrm{~mol} / \mathrm{L})$ and $2.5 \mathrm{~mL}$ of $1 \%$ potassium ferricyanide $\left(\mathrm{K}_{3} \mathrm{Fe}(\mathrm{CN})_{6}\right)$ solution were added to the polysaccharide solutions with different concentration. After rapid mixing, $45^{\circ} \mathrm{C}$ water bath for $30 \mathrm{~min}$, immediate cooling, and adding $3.0 \mathrm{~mL}$ of $10 \%$ trichloroacetic acid (TCA) solution, the solution was centrifuged at $6000 \mathrm{rpm}$ for $20 \mathrm{~min}$. $3.0 \mathrm{~mL}$ of the supernatant was mixed with $2.0 \mathrm{~mL}$ of distilled water and $1.0 \mathrm{~mL}$ of $0.1 \%$ ferric chloride $\left(\mathrm{FeCl}_{3}\right)$ solution and measured for its absorbance at $700 \mathrm{~nm}$ wavelength. The higher absorbance means the reducing power is stronger. In the comparison with distilled water as negative control and vitamin $\mathrm{C}$ (VC) solution as positive control, the experiment was repeated three times for each sample and the average value was calculated.

2.4.2. Determination of 1,1-Diphenyl-2-picrylhydrazyl Radical 2,2-Diphenyl-1-(2,4,6-trinitrophenyl)hydrazyl (DPPH) Radical Scavenging Activity. According to [12], the reaction system included $1.0 \mathrm{~mL}$ of polysaccharide solution with different concentrations, $2.0 \mathrm{~mL}$ of $0.2 \mathrm{mmol} / \mathrm{L} \mathrm{DPPH}$-ethanol solution and $2 \mathrm{~mL}$ of $95 \%$ ethanol. All were mixed well and reacted in the dark for $30 \mathrm{~min}$. The absorbance was measured at a wavelength of $517 \mathrm{~nm} .2 .0 \mathrm{~mL}$ of $95 \%$ ethanol solution was used instead of DPPH as blank sample. The solution in control group was $2.0 \mathrm{~mL}$ of DPPH solution mixed with $3.0 \mathrm{~mL}$ of $95 \%$ ethanol. Vitamin E (VE) was applied as positive control. The lower absorbance of the reaction system indicates the stronger DPPH radical scavenging activity. The rate of DPPH radical scavenging is calculated according to the following formula: $I / \%=\left(\left(A_{0}-A_{1}\right) * 100\right) / A_{0}$.

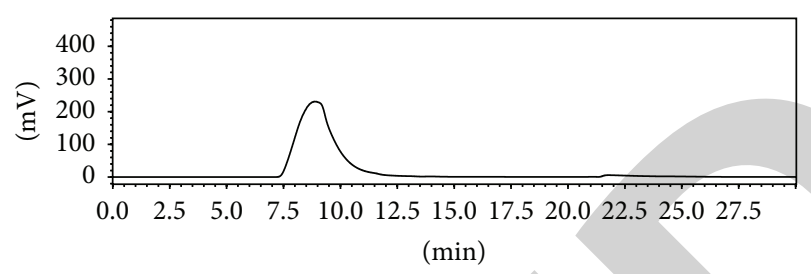

FIGURe 2: Purity identification of truffle polysaccharide (PST-W) by HPLC-UV.

$I / \%$ represents the percentage of clearance rate; $A_{1}$ is the absorbance of sample group; $A_{0}$ means the absorbance of control group. All samples were tested in triplicate, and the average value was calculated.

2.4.3. Determination of $\mathrm{O}_{2}^{-\bullet}$ Clearing Ability. Using pyrogallol autoxidation method [13], pyrogallol in alkaline conditions can cause autoxidation. To each tube containing $6.0 \mathrm{~mL}$ of Tris- $\mathrm{HCl}$ buffer $(50 \mathrm{mmol} / \mathrm{L}, \mathrm{pH}=8.1), 0.5 \mathrm{~mL}$ of polysaccharide solution with different concentrations was added. The mixture is in the water bath of $37^{\circ} \mathrm{C}$ for $10 \mathrm{~min}$. Then $1.0 \mathrm{~mL}$ of the hydrochloric acid solution of pyrogallol $(7 \mathrm{mmol} / \mathrm{L})$ was added, shaken, and reacted precisely for $4 \mathrm{~min}$. After that, the reaction was quenched with $0.5 \mathrm{~mL}$ of concentrated $\mathrm{HCl}$. The absorbance was measured at a wavelength of $325 \mathrm{~nm}$. The distilled water was used as blank sample, and VC was used as positive control. $\mathrm{O}_{2}{ }^{-\bullet}$ clearing ability was estimated based on the following formula: $I / \%=$ $\left(\left(A_{0}-A\right) * 100\right) / A_{0} . I / \%$ represents the percentage of clearance rate; $A_{0}$ is the absorbance of control group; $A$ indicates the absorbance of sample solution. All samples were tested in triplicate, and the average value was calculated.

2.5. Statistical Analysis. $t$-test was used to make comparisons between the mean values of independent samples. The analysis was performed by applying the SPSS statistics system (version 16.5). Significance was defined as $p<0.05$ and the variables are presented as the mean \pm SD.

\section{Results}

3.1. The Yield of Polysaccharides (Dry Weight). The yields of crude polysaccharides-1, crude polysaccharides-2, and crude polysaccharides-3, measured by phenol-sulfuric acid method, were $3.48 \%, 2.13 \%$, and $1.79 \%$, respectively. The yield of pure PST-W was $0.41 \%$. In this process (Figure 1), three crude polysaccharides were obtained and comparing their antioxidization abilities with PST-W was attempted.

The carbohydrate polymer (PST-W) might be isolated as neutral polysaccharides. After the purification of SephadexG100 column chromatography, the main peaks were collected, concentrated, and finally analyzed by HPLC-UV (Figure 2). In our previous study about molecular weight of polysaccharides [7], several dextran standards with different molecular weights got different retention time $(R T)$ in the same HPLC conditions. So, according to the relationship between $R T$ and molecular weight, the formula can be obtained as $\operatorname{Ig}(M)=$ 


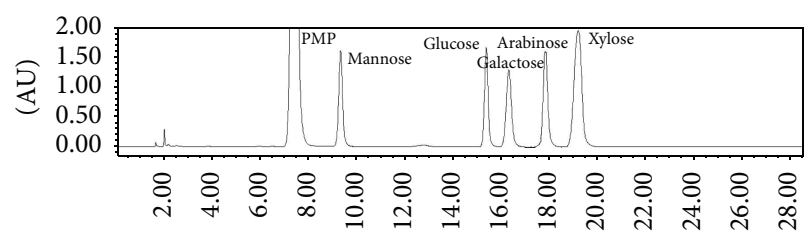

(a)

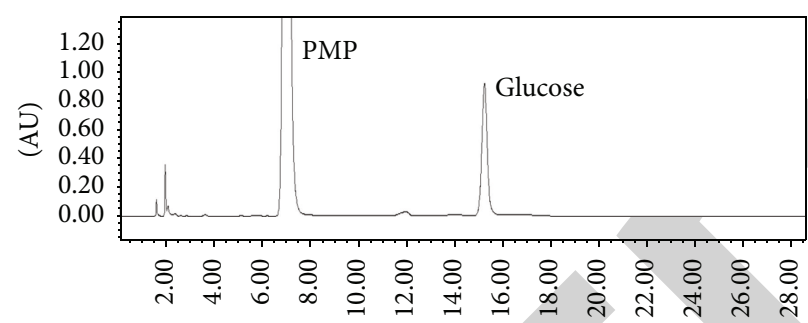

(b)

FIGURE 3: HPLC spectrum of acetylated aldononitrile derivatives of (a) mixed standard monosaccharide and (b) PST-W.

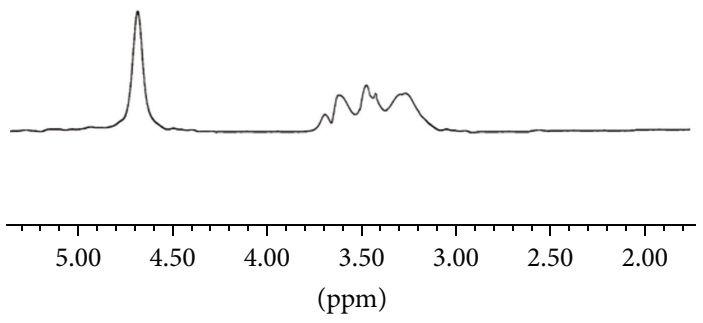

(A)

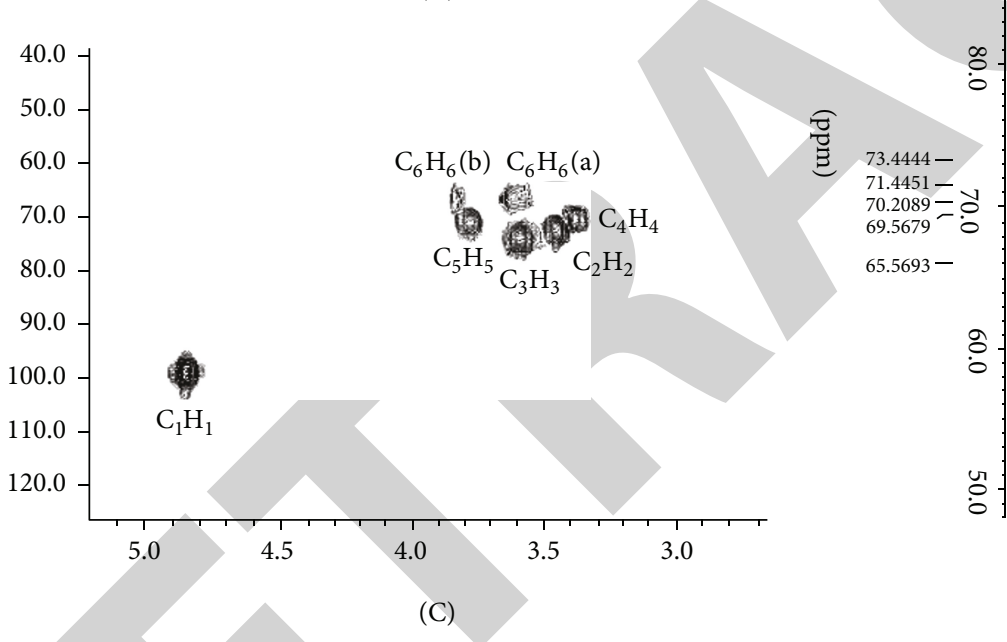

Figure 4: The (A) ${ }^{1} \mathrm{H}-\mathrm{NMR},(\mathrm{B}){ }^{13} \mathrm{C}-\mathrm{NMR}$, and (C) HMQC spectra $\left(\mathrm{D}_{2} \mathrm{O}, 500 \mathrm{MHz}\right)$ of PST-W.

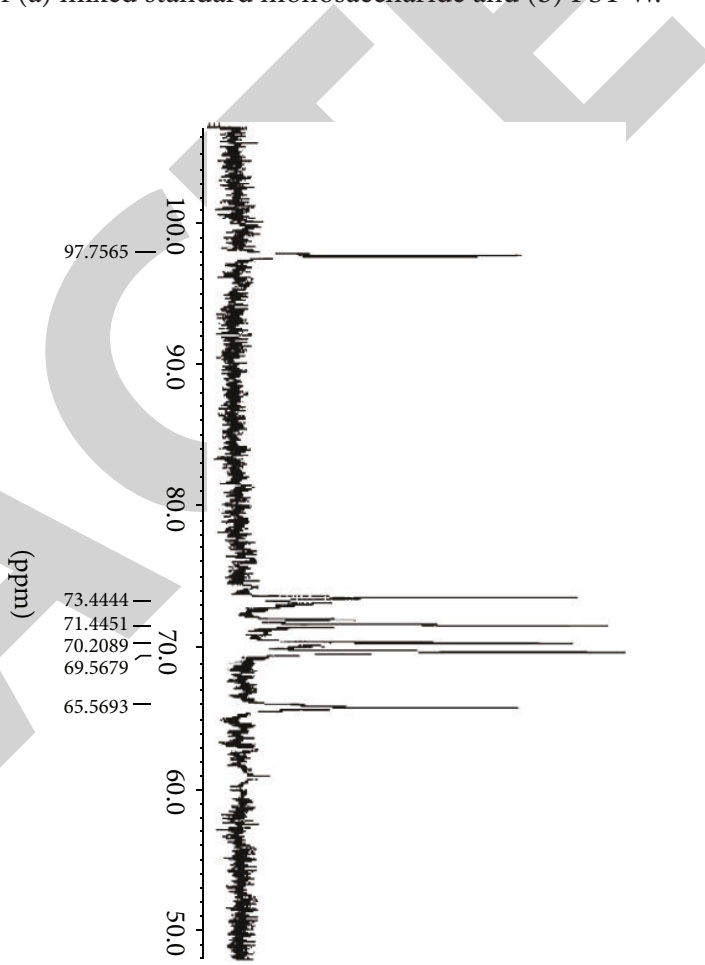

(B)

\section{. \\ $-0.0817 R T+6.587$. The molecular weight of PST-W was calculated as $7.29 \times 10^{5}$ Da separately.}

\subsection{Structural Characteristics of Polysaccharides}

3.2.1. Monosaccharide Compositions. By the quantitative method with external standard, PST-W was glucan only containing D-glucoses (Figure 3).

3.2.2. The Methylation Analysis of PST-W. The sample of PSTW was fully methylated, followed by complete acid hydrolysis, and finally made into acetylated derivatives for GC-MS analysis, and the results were shown in Table 1. Referencing the literature from Guo et al. [10], the only derivative of 1, 5, 6-tri-O-acetyl-2, 3, 4-tri-O-methyl-D-glucitol could be detected obviously in PST-W. It could be inferred that PST-W was mainly composed of $(1 \rightarrow 6)$-linked glucose group.
3.2.3. The NMR Analysis of PST-W. As shown in Figure 4, NMR analysis was carried out to further verify the molecular structure of PST-W [10]. There were six peaks with basically equal height in PST-W ${ }^{13} \mathrm{C}-\mathrm{NMR}$ spectrum. From low field to high field they were $97.74,73.42,71.43,70.21,69.57$, and 65.59. The chemical shift of 97.74 was the signal peak of $\mathrm{C} 1$ on the terminus [14]. It was approved again that PST-W was composed of $\alpha$-D-glucose and it was identical to the results of infrared spectra. There was signal peak of C6 substitution at 65.59 , with no other signal peaks at 80.00 . So it could be concluded that there was no $\mathrm{C} 2, \mathrm{C} 3$, or $\mathrm{C} 4$ substitution existing. This result was consistent with the methylation [15]. The experimental results of ${ }^{1} \mathrm{H}-\mathrm{NMR}$ and ${ }^{13} \mathrm{C}-\mathrm{NMR}$ showed that PST-W might be a linear glucan connected by $\alpha$-D- $(1 \rightarrow$ $6)$, and its structure could be determined as follows: $[\rightarrow 6) \alpha$ D-Glcp $(1 \rightarrow 6) \alpha$-D-Glcp $(1 \rightarrow]_{n}$. 


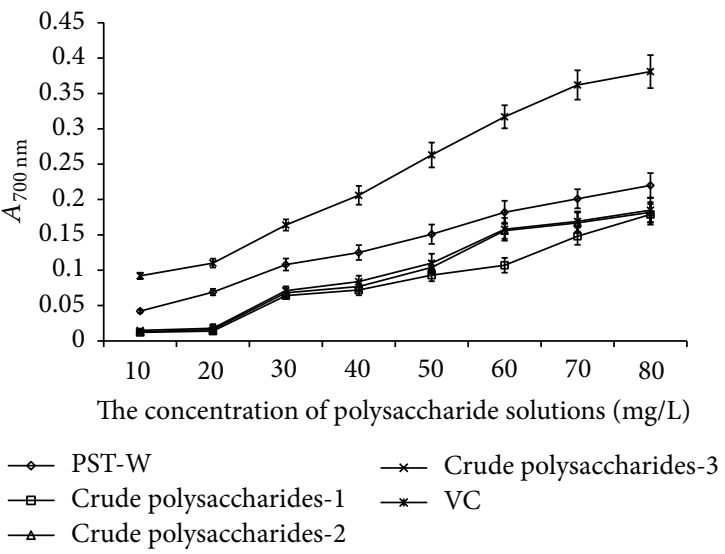

(a)

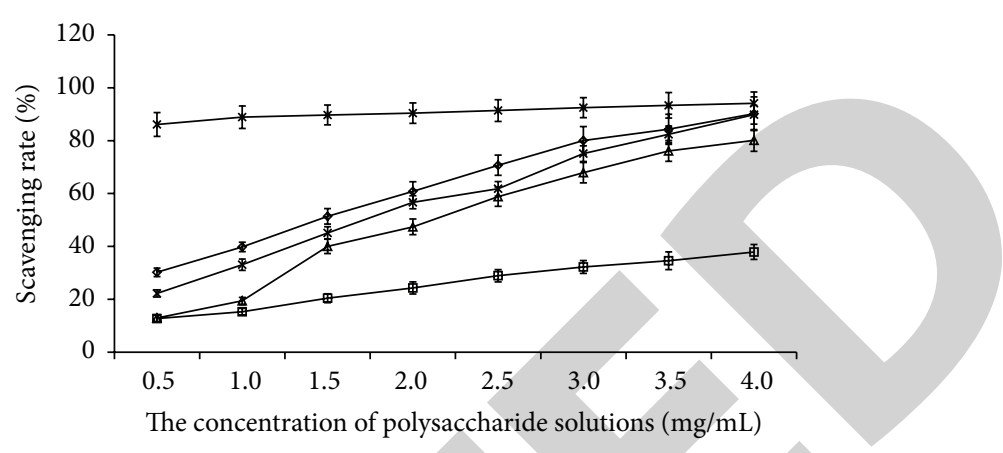

$\rightarrow$ PST-W $\rightarrow$ Crude polysaccharides-1

$\triangle$ Crude polysaccharides- $\rightarrow$ Crude polysaccharides-3

$\rightarrow \mathrm{VE}$

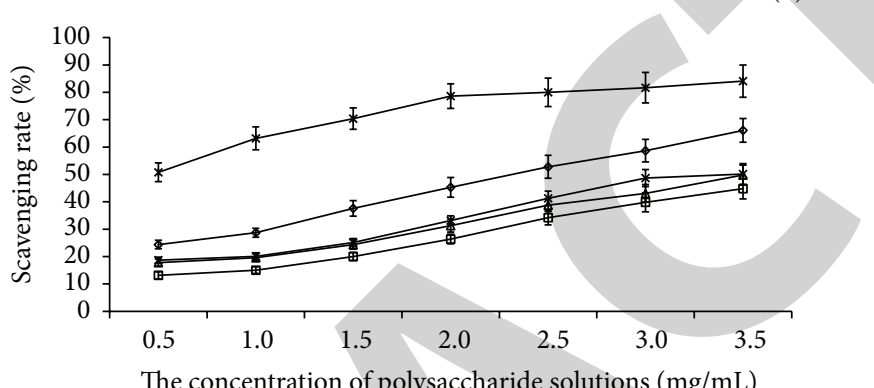

(b)

$\begin{array}{ll}\rightarrow \text { PST-W } & \rightarrow \text { Crude polysaccharides-1 } \\ \rightarrow \text { Crude polysaccharides- } \quad \rightarrow \text { Crude polysaccharides-3 }\end{array}$

(c)

FIGURE 5: Antioxidant activities of PST-W and crude polysaccharides on potassium ferricyanide ((a): total reducing power), DPPH radical (b), and superoxide anion radical (c) with vitamin C or vitamin $\mathrm{E}(\mathrm{VC} / \mathrm{VE})$ as a positive control. Data are mean $\pm \mathrm{SD}$ values $(n=3)$.

TABLE 1: The GC-MS results of methylated PST-W.

\begin{tabular}{lcccc}
\hline \multirow{2}{*}{ Methylated sugar residue } & Retention time (min) & \multicolumn{2}{c}{ Major ion peak of MS $(\mathrm{m} / z)$} & References $[10]$ \\
& & PST-W & Glycosidic bond chaining \\
\hline $2,3,4-\mathrm{Me}_{3}$-Glc & 25.239 & $101,117,129,161,189,233$ & $101,117,129,161,189,233$ & $\rightarrow 6)$ Glc $(1 \rightarrow$ \\
\hline
\end{tabular}

\subsection{In Vitro Antioxidant Activity}

3.3.1. Determination of Total Reducing Capacity. Considering that the reducing ability is obviously positive related to antioxidant activity, the absorbance of reactive products at $700 \mathrm{~nm}$ indicates the intensity of reducing ability. The results of each sample were shown in Figure 5(a). It seemed that, along with the purification procedure of crude polysaccharide, the crude extract with higher purity inferred to stronger reducing power. So, the antioxidant effects of polysaccharide extracts could be listed as VC > PST-W > crude polysaccharides- $3>$ crude polysaccharides$2>$ crude polysaccharides- 1 . The activities of three crude polysaccharides were similar and weak.

3.3.2. Determination of DPPH Radicals Scavenging Activity. DPPH radicals are a kind of stable aromatic radicals. The scavenging activity of antioxidants on DPPH is generally acknowledged as the total ability on clearing radicals [16]. All samples showed their abilities on scavenging DPPH radicals (Figure 5(b)). When the concentration of polysaccharides samples was $4.0 \mathrm{mg} / \mathrm{mL}$, the clearance rates of PST-W, crude polysaccharides- 2 , and crude polysaccharides- 3 were $90.2 \%$, $80.1 \%$, and $89.8 \%$, close to the $94.1 \%$ of VE. The clearance ability of crude polysaccharides -1 at $4.0 \mathrm{mg} / \mathrm{mL}$ also achieved $37.9 \%$.

3.3.3. Determination of $\mathrm{O}_{2}^{-\bullet}$ Clearing Ability. $\mathrm{O}_{2}^{-\bullet}$ is the first one of all oxygen radicals and can product other oxygen radicals through series of reactions. It is highly toxic, and the clearing capacity for extra $\mathrm{O}_{2}^{-\bullet}$ is particularly significant [17]. Compared with VC, the clearing ability of all crude polysaccharides samples was relatively weak (Figure 5(c)). It is surmised that polysaccharide might only react with $\mathrm{O}_{2}{ }^{-\bullet}$ by its hydrogen on reactive hydroxyl, which could not inhibit the product of $\mathrm{O}_{2}^{-\bullet}$ fundamentally. 
TABLE 2: IC $_{50}$ values of PST-W and crude polysaccharides for scavenging DPPH and superoxide anion radical ( $\mathrm{mg} / \mathrm{mL})$.

\begin{tabular}{lcc}
\hline Samples & DPPH radical & $\mathrm{O}_{2}^{-\bullet}$ \\
\hline PST-W & $2.81 \pm 0.008$ & $4.73 \pm 0.017$ \\
Crude polysaccharides-1 & $6.48 \pm 0.041$ & $7.55 \pm 0.036$ \\
Crude polysaccharides-2 & $4.17 \pm 0.020$ & $7.01 \pm 0.027$ \\
Crude polysaccharides-3 & $3.44 \pm 0.012$ & $6.56 \pm 0.015$ \\
VE & $0.15 \pm 0.003$ & - \\
VC & - & $0.87 \pm 0.002$ \\
\hline
\end{tabular}

Means $\pm \operatorname{SD}(n=3)$ followed by $*, * *, * * *$ are significantly different from values obtained for crude polysaccharides- $1\left({ }^{*} p<0.05 ;{ }^{* *} p<0.01 ;{ }^{* * *} p<\right.$ $0.001 ;$-test).

3.3.4. Value of $I C_{50}$. Each assay on antioxidant activity was reproductive and repeatable. According to Table 2, the antioxidant capacities of PST-W and crude polysaccharides on scavenging DPPH and superoxide anion radical were calculated in the form of $\mathrm{IC}_{50}$. The values of $\mathrm{IC}_{50}$ indicated that all of PST-W, crude polysaccharides-2, and crude polysaccharides3 were relatively good scavenger for $\mathrm{DPPH}$ radicals with $\mathrm{IC}_{50}$ of $2.81,4.17$, and $3.44 \mathrm{mg} / \mathrm{mL}$, respectively. However, $\mathrm{O}_{2}{ }^{-}$ clearing abilities of PST-W and crude polysaccharides were obviously weaker than their capacities on DPPH.

\section{Discussion and Conclusion}

In recent research [18], $5 \mathrm{mg} / \mathrm{mL}$ polysaccharide extracts of Perigord Truffle (PEPT) demonstrated its high scavenging abilities on hydroxyl radicals and $\mathrm{DPPH}$ with $\mathrm{EC}_{50}$ of $0.73 \mathrm{mg} / \mathrm{mL}$ and $1.12 \mathrm{mg} / \mathrm{mL}$, respectively. In the study against redox reaction induced by potassium ferricyanide, ferric chloride, and trichloroacetic acid, $\mathrm{EC}_{50}$ of PEPT was $2.46 \mathrm{mg} / \mathrm{mL}$. In another study, PEPT was divided into three groups according to molecular size by dialysis membrane: TIP-III group included the ingredients of PEPT with molecular weight $>100 \mathrm{Da}$; TIP-II group contained components of PEPT with molecular weight between 50 and $100 \mathrm{Da}$; TIP-I group were compositions of PEPT with molecular weight of $<50 \mathrm{Da}$ [19]. The TIP group with smaller molecular weight resulted in higher clearance and stronger antioxidant activities on DPPH radicals, ${ }^{\circ} \mathrm{OH}, \mathrm{O}_{2}^{-\cdot}$, and iron ions (TIPIII > TIP-II > TIP-I).

To the best of our knowledge, this was the first investigation on the chemical characteristics, monosaccharide composition, and antioxidant activities of polysaccharide PST-W from Perigord Truffle (Tuber huidongense). PST-W is the main soluble polysaccharide of truffle. In this study, our results indicated the presumed molecular structure of PST-W was $[\rightarrow 6) \alpha$-D-Glcp $(1 \rightarrow 6) \alpha$-D-Glcp $(1 \rightarrow]_{n}$, wherein the value of $n$ could be calculated to be about $2 \times 10^{3}$. In the determination of total reducing capacity, the reducing abilities of polysaccharide extracts could be listed as VC > PST-W > crude polysaccharides- $3>$ crude polysaccharides- $2>$ crude polysaccharides- 1 . All of PST-W, crude polysaccharides- 2 , and crude polysaccharides- 3 were relatively good scavenger for DPPH radicals. However, $\mathrm{O}_{2}{ }^{-}$ clearing abilities of PST-W and crude polysaccharides were obviously weaker. For the antioxidant activities of PST-W and polysaccharide extracts, the activities of total crude extract were the worst, indicating that the impurities might negatively affect the antioxidant activity. Thus, the separation and purification of polysaccharides were significant to increase the antioxidant activity in some degree.

It was proposed that the possible antioxidant mechanism of PST-W may involve hydrogen donation to break chain reactions and free radical scavenging ability resulting from the abstraction of anomeric hydrogen from the internal monosaccharide units of polysaccharides [20]. Most importantly, the biological activities of polysaccharides are associated tightly with molecular weight, uronic acid, monosaccharide composition, degree of substitution and branching, structure, and conformation. In particular, the antioxidant activities of different polysaccharide fractions recently were correlated positively with the increasing sulfate group content $[21,22]$ and the decreasing molecular weight of polysaccharides [23]. Considering that there is no sulfate group in the branch of PST-W, it may answer for its relative week antioxidant activity.

It was also demonstrated that the Chinese truffle (Tuber huidongense) is a healthcare food and a source of natural antioxidants, and further investigation of its antioxidant properties in vivo and other studies of the biological activities of these polysaccharides are in progress. Further studies on their application in the food, medical, and cosmetic industries are worth exploration.

\section{Ethical Approval}

This study received the approval of local Animal Ethics Committee (no. 2010021137).

\section{Competing Interests}

The authors declare that there are no competing interests regarding the publication of this paper.

\section{Acknowledgments}

This work was supported by the Public Welfare Technology Application Research Project of Zhejiang Province under Grant no. 2015C37122 and the National Natural Science Foundation of China under Grant no. 81373139. The authors thank all staff members in Department of Food Science for the technical guide of equipment and cooperation of projects.

\section{References}

[1] H. J. Hu, P. Z. Li, T. Lin, B. Q. Hang, and Y. W. Guo, "Effect of block polysaccharide on mouse tumors and the immune system," Journal of China Pharmaceutical University, vol. 55, pp. 289-292, 1994

[2] Y.-J. Tang, L.-L. Zhu, R.-S. Liu, H.-M. Li, D.-S. Li, and Z.-Y. $\mathrm{Mi}$, "Quantitative response of cell growth and Tuber polysaccharides biosynthesis by medicinal mushroom Chinese truffle Tuber sinense to metal ion in culture medium," Bioresource Technology, vol. 99, no. 16, pp. 7606-7615, 2008. 
[3] W. Zhao, X.-H. Wang, H.-M. Li et al., "Isolation and characterization of polysaccharides with the antitumor activity from Tuber fruiting bodies and fermentation system," Applied Microbiology and Biotechnology, vol. 98, no. 5, pp. 1991-2002, 2014.

[4] Q. Luo, J. Zhang, L. Yan et al., "Composition and antioxidant activity of water-soluble polysaccharides from tuber indicum," Journal of Medicinal Food, vol. 14, no. 12, pp. 1609-1616, 2011.

[5] M. Guo, L. W. Tang, J. P. Yan, and I. Chagan, "Main physiological activities of Truffles and research progress of active substances production," Science and Technology of Food Industry, vol. 21, pp. 403-407, 2012 (Chinese).

[6] S. Q. Zhang and J. Q. Kan, "Aroma Compound Analysis of Tuber huidongense by GC-MS," Food Science, vol. 32, pp. 281-285, 2011 (Chinese).

[7] S. Q. Zhang, "Purification and molecular weight determination of HUI DONG truffles polysaccharide," Food and Fermentation Technology, vol. 46, pp. 97-100, 2010 (Chinese).

[8] C.-Y. Tian and G.-L. Wang, "Isolation, purification and physical-chemical properties of polysaccharides from sweet potatoes," Journal of Dalian University of Technology, vol. 49, no. 1, pp. 44-47, 2009 (Chinese).

[9] X. Wu, W. Jiang, J. Lu, Y. Yu, and B. Wu, "Analysis of the monosaccharide composition of water-soluble polysaccharides from Sargassum fusiforme by high performance liquid chromatography/electrospray ionisation mass spectrometry," Food Chemistry, vol. 145, pp. 976-983, 2014.

[10] S. D. Guo, Y. Chen, J. Xu et al., "Isolation, purification and structural elucidation of the exopolysaccharides from Antarctic fungus Oidiodendron truncatum," Periodical of Ocean University of China, vol. 40, pp. 5-10, 2010 (Chinese).

[11] I. F. F. Benzie and J. J. Strain, "The ferric reducing ability of plasma (FRAP) as a measure of 'antioxidant power': the FRAP assay," Analytical Biochemistry, vol. 239, no. 1, pp. 70-76, 1996.

[12] C. L. Lin, C. C. Wang, S. C. Chang, B. S. Inbaraj, and B. H. Chen, "Antioxidative activity of polysaccharide fractions isolated from Lycium barbarum Linnaeus," International Journal of Biological Macromolecules, vol. 45, no. 2, pp. 146-151, 2009.

[13] S. A. B. E. van Acker, G. P. van Balen, D.-J. van den Berg, a. bast, and W. J. F. van der Vijgh, "Influence of iron chelation on the antioxidant activity of flavonoids," Biochemical Pharmacology, vol. 56, no. 8, pp. 935-943, 1998.

[14] S.-I. Hakomori, "A rapid permethylation of glycolipid, and polysaccharide catalyzed by methylsulfinyl carbanion in dimethyl sulfoxide," Journal of Biochemistry, vol. 55, no. 2, pp. 205-208, 1964.

[15] R. K. Purama, P. Goswami, A. T. Khan, and A. Goyal, "Structural analysis and properties of dext ran produced by Leuconostoc mesenteroides NRRL B-640," Carbohydrate Polymers, vol. 76, no. 1, pp. 30-34, 2009.

[16] J.-M. Yi, M.-S. Kim, S.-W. Seo, K.-N. Lee, C.-S. Yook, and H.-M. Kim, "Acanthopanax senticosus root inhibits mast celldependent anaphylaxis," Clinica Chimica Acta, vol. 312, no. 1-2, pp. 163-168, 2001.

[17] H. Yuan, W. Zhang, X. Li et al., "Preparation and in vitro

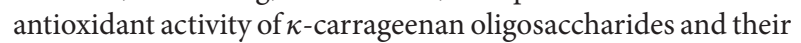
oversulfated, acetylated, and phosphorylated derivatives," Carbohydrate Research, vol. 340, no. 4, pp. 685-692, 2005.

[18] Q. L. Kong, J. Fan, and T. R. Zhao, “Optimization of extraction technique of polysaccharides from truffles by response surface methodology and determination of crude polysaccharide antioxidant activity," Food and Fermentation Industries, vol. 38, pp. 175-179, 2012 (Chinese).

[19] J. M. Yue, B. Pu, A. J. Chen, and X. Y. Liu, "Antioxidant activity in vitro of polysaccharides with different molecular weights from truffles," Food Science, vol. 34, pp. 127-131, 2013 (Chinese).

[20] Y. Yamaguchi, S. Kagota, K. Nakamura, K. Shinozuka, and M. Kunitomo, "Antioxidant activity of the extracts from fruiting bodies of cultured Cordyceps sinensis," Phytotherapy Research, vol. 14, no. 8, pp. 647-649, 2000.

[21] H. Qi, L. Huang, X. Liu, D. Liu, Q. Zhang, and S. Liu, "Antihyperlipidemic activity of high sulfate content derivative of polysaccharide extracted from Ulva pertusa (Chlorophyta)," Carbohydrate Polymers, vol. 87, no. 2, pp. 1637-1640, 2012.

[22] S. L. Xiong, A. Li, N. Huang, F. Lu, and D. Hou, "Antioxidant and immunoregulatory activity of different polysaccharide fractions from tuber of Ophiopogon japonicus," Carbohydrate Polymers, vol. 86, no. 3, pp. 1273-1280, 2011.

[23] R. Xing, S. Liu, Z. Guo et al., "Relevance of molecular weight of chitosan and its derivatives and their antioxidant activities in vitro," Bioorganic and Medicinal Chemistry, vol. 13, no. 5, pp. 1573-1577, 2005. 